\title{
Acute Promyelocytic Leukemia in Pediatric Population: A Rare Presentation
}

\author{
Rabiah Asghar, Javera Tariq, Shahzad Ali Jiskani*, Sundas Ali, Aneela Zafar \\ Department of Pathology, Pakistan Institute of Medical Sciences Islamabad, Pakistan.
}

\begin{abstract}
Acute Promyelocytic Leukemia (APL) is a very uncommon type of acute myeloid leukemiacomprising less than $10 \%$ of pediatric population. Acute Promyelocytic leukemia is a neoplastic proliferation of abnormal promyelocytes in bone marrow, caused by cytogenetic abnormality $\mathrm{t}(15 ; 17)$. Majority of patients $(80 \%)$ have long term survival, and death occurs in approximately $10 \%$ of patients in early course of the disease; mainly because of hemorrhage. Hemorrhagic complications can be reduced by appropriate therapy if started timely, which ultimately reduces the risk of death.We report a case of 7 years old boy with complaints of fever off and on for past 06 months, bruises and swelling on left leg for 1 week, blood containing vomiting for 1day. He was diagnosed as APL on bone marrow biopsy.
\end{abstract}

Keywords: Acute promyelocytic leukemia, Paediatric, Retinoic acid syndrome, All-Trans retinoic acid, FAB AML-M3, Sudan Black-B.

\section{INTRODUCTION}

Acute promyelocytic leukemia (APL), comprises $5 \%$ to $8 \%$ of acute myeloid leukemia (AML) cases. In the United States, it accounts for $4 \%$ to $8 \%$ of AML in children. The peak age in pediatric population is 9 to 12 years old children and predominance of females is seen [1]. Risk of AML is increased by presence of certain predisposing factors such as genetic, environmental, and acquired causes [2]. White blood cell count (WBC) of about $20,000 / \mathrm{mm} 3$ is associated with a better prognosis, and WBC count of $100,000 / \mathrm{mm} 3$ is related to adverse outcomes [3].

Acute myeloid leukemia is diagnosed by presence of certain features e.g. morphology, cytogenetics and immunophenotyping. Unlike other forms of AML, APL can cause coagulopathy and death if delay in diagnosis occurs. As per French American - British (FAB) classification of acute myeloid leukemia, APML is morphologically considered as AML M3 and is characterized as neoplastic proliferation of promyelocytes in bone marrow. Expression of abnormal promyelocytes in the bone marrow is seen due to balanced reciprocal translocation $\mathrm{t}(15 ; 17)(\mathrm{q} 24.1 ; \mathrm{q} 21.2)$ [4]. Survival rate of acute promyelocytic leukemia (75-80\%) in pediatric age group is relatively improved due to introduction of targeted therapy which includes all-trans retinoic acid (ATRA) and chemotherapy [5].

\section{CASE REPORT}

A seven year old boy resident of Swabi presented in Pakistan Institute of Medical Sciences (children hospital) with complaints of fever off and on for past 06 months, bruises and swelling on left leg for 1 week, blood in vomitus for 1day.On physical examination, he was pale without any lymphadenopathy or organomegaly.

*Address correspondence to this author at the Department of Pathology, Pakistan Institute of Medical Sciences Islamabad, Pakistan.

E-mail: shahzadbaloach289@gmail.com

\section{LABORATORY FINDINGS}

Hemoglobin was $4.2 \mathrm{~g} / \mathrm{dL}$ (11.8-14.7), red blood cell count was $1.54 \mathrm{X} 106 / \mu \mathrm{L}(4.10-5.20)$, white blood cell count was $1.7 \mathrm{X} 103 / \mu \mathrm{L}$ (3.8-10.4), hematocrit was $13.9 \%(34-42 \%)$, mean corpuscular volume (MCV) was $90.3 \mathrm{fL}(77.8-91.1)$, mean corpuscular hemoglobin (MCH) was 27.3 pg (27-31), mean corpuscular hemoglobin concentration $(\mathrm{MCHC})$ was $30.2 \mathrm{~g} / \mathrm{dL}$ (32-36), red cell distribution width (RDW) was $15.1 \%$ (11.4-13.5\%). Platelet count was 10 X $109 / \mathrm{L}$ (187-400). Reticulocyte count was 1.5\%(1-2 \%). Peripheral film showed a dimorphic blood picture due to recent transfusion.

Differential Leucocyte Count showed Neutrophils: 04\%, Lymphocytes: 26\%, Monocytes: 02\%, Eosinophils: 03\%, Myelocytes: $05 \%$, Atypical mononuclear cells: 60\% (abnormal promyelocytes and blasts with Auer rods, Faggots cells containing bundles of Auer Rods). Platelets were decreased on smear. Peripheral film findings are depicted in Fig. (1).

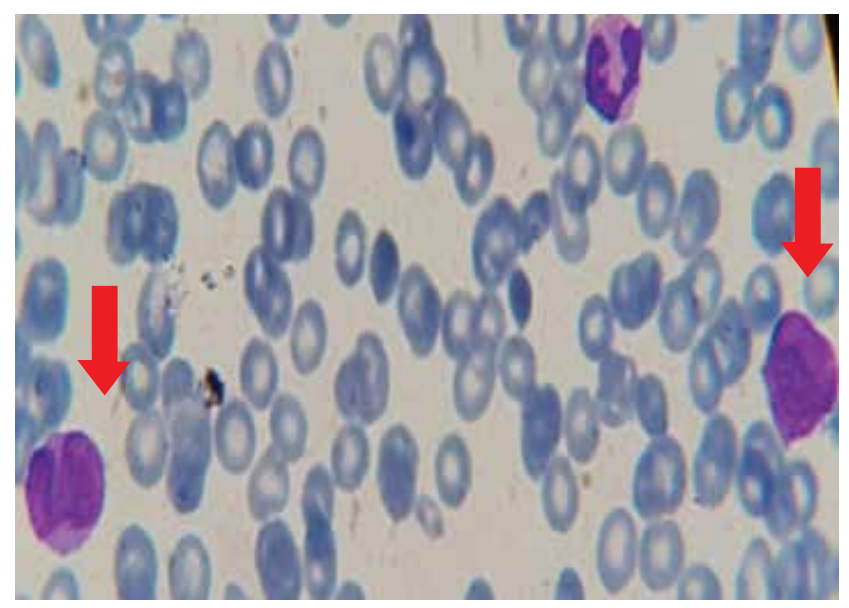

Fig. (1). Peripheral Smear Showing Abnormal Promyelocytes with Auer Rods.

www.njhsciences.com 
Bone marrow aspirate was very hypercellular with $45 \%$ atypical promyelocytes (large cells with irregular margins, cytoplasm filled with large dense granules obscuring the nuclear margins, Auer rods present, some Irish bun shaped nuclei were seen). Blasts were $11 \%$. Erythroid, maturing myeloid and megakaryocytic cell lines were depressed. Bone Marrow findings are shown in Fig. (2 A, B).

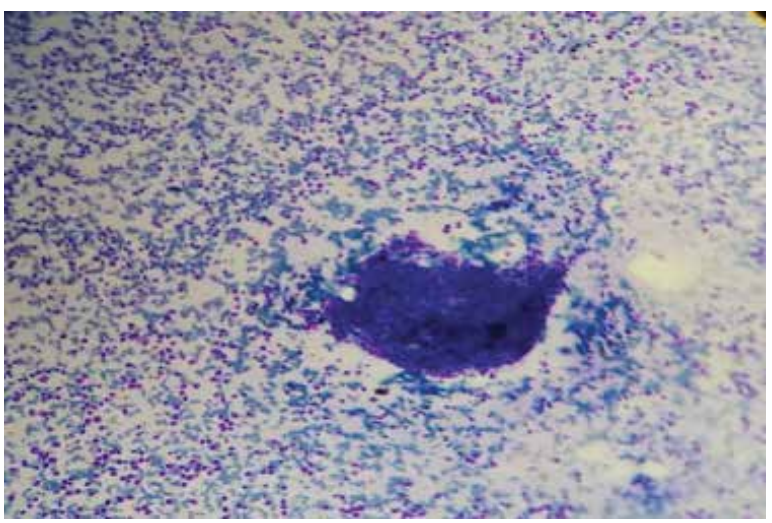

Fig. (2A). Bone Marrow Aspirate at 10X.

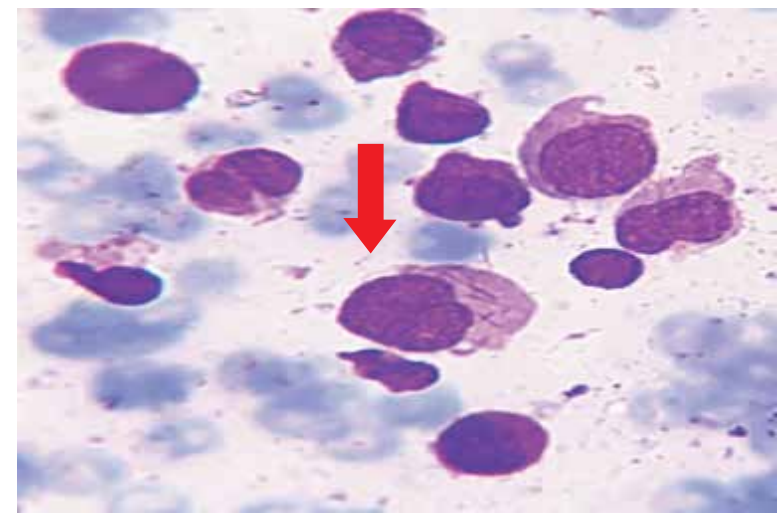

Fig. (2B). Faggot Cells at 1000X.

Cytochemical stain Sudan Black-B was strongly positive in abnormal promyelocytes and blast cells as shown in Fig. (2C).

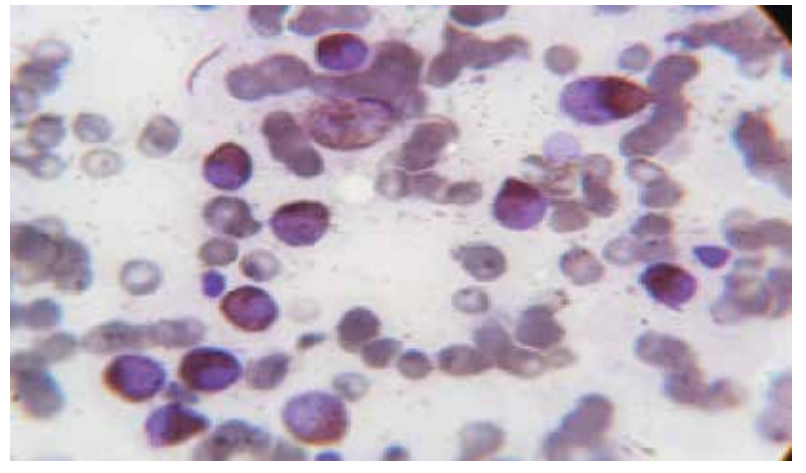

Fig. (2C). Strong SudanBlack B Positivity at 1000X.

\section{DISCUSSION}

Acute promyelocytic leukemia (APL) is subtype of acute myeloid leukemiaidentified by the arrest at promyelocyte stage of hematopoiesis. APL is a rare disease and APL is a very uncommon type of AML, the number of cases in pediatric population with APL is quite small. However, if it is diagnosed earlier and managed timely the outcome of children with APL is as good as that of adults [6]. $\mathrm{t}(15 ; 17)$ PML RARA is being associated with pediatric APL cases; especially patients under 10 years. Patients frequently presented with leukopenia or pancytopenia, with symptoms including weakness, fatigue, pallor, fever,infection, and bleeding [1]. APL is less likely to be associated with extramedullary manifestations including hepatomegaly, lymphadenopathy and splenomegaly, as compared to other types of acute myeloid leukemia [1].

Literature shows that a case of APL was reported in a four-year old girl who presented to Emergency Department with bruising, petechial rash and bleeding gums [7]. Similarly, Schwartz et al reported a case of APL in a previously healthy 10-year-old girl with symptoms of headache, vomiting, loss of ambulation, mental sluggishness and lower limb bruising [1].Another rare case was reported by Nair et al. who described a paediatric patient with APL who presented with lytic lesions of iliac bone and skull at disease onset [8].

\section{CONCLUSION}

APL is a very rare presentation inpediatric age group, and it is characterized by typical signs and symptoms of leukemia accompanied by bleeding manifestations/disseminated intravascular coagulopathy (DIC). It is suggested to diagnose this type of cases with Real time PCR. Treatment should be initiated at initial stages to combat high mortality rate.

\section{CONFLICT OF INTEREST}

Declared none.

\section{ACKNOWLEDGEMENTS}

We acknowledge all our fellow colleagues.

\section{AUTHORS' CONTRIBUTION}

Rabiah Asghar: Concept, Study Designing, Planning, Discussion, Manuscript Writing.

Javera Tariq: Planning, Study Conduction, Analysis.

Shahzad Ali Jiskani: Experimentation, Interpretation, Discussion, Manuscript Writing.

Aneela Zafar: Analysis, Discussion.

Sundas Ali: Analysis, Disucussion. 


\section{REFERENCES}

[1] Schwartz KR, Hanson JM, Friedmann AM. Pediatric Acute promyelocytic leukemia presenting to the emergency department as refusal to ambulate. Case Rep Emerg Med 2018; 2018: 5241425. DOI: $10.1155 / 2018 / 5241425$

[2] Fadoo Z, Mushtaq N, Alvi S, Ali M. Acute myeloid leukaemia in children: Experience at a tertiary care facility of Pakistan. J Pak Med Assoc 2012; 62(2): 125.

[3] Sah KP, Bhattarai S. Acute promyelocytic leukaemia. J Nepal Paediatr Soc 2017; 37(3): 270-2. DOI: 10.3126/jnps.v37i3.18553

[4] Adams J, Nassiri M. Acute promyelocytic leukemia: A review and discussion of variant translocations. Arch Pathol Lab Med 2015; 139(10): 1308-13. DOI: 10.5858/arpa.2013-0345-RS

[5] Zhang L, Samad A, Pombo-de-Oliveira MS, et al. Global characteristics of childhood acute promyelocytic leukemia. Blood Rev 2015; 29(2): 101-25. DOI: 10.1016/j.blre.2014.09.013

[6] Singh SM, Parihar M, Arora N, et al. Diagnosis of variant RARA translocation using standard dual - color dual - fusion PML/RARA FISH probes: An illustrative report. Hematol Oncol Stem Cell Ther 2019; 12(1): 50-3

[7] Kushtagi AV, Bhalodia MJ, Karigoudar MH, Savle J. Acute promyelocytic leukemia in four year old female child-a case report. J Krishna Institue Med Sci (JKIMSU) 2014; 3(2): 140-3.

[8] Nair M, Kusumakumary P, Nair PS. Rare presentation of pediatric acute promyelocytic leukemia as multiple lytic bone lesions: case report and review of literature. J Cancer Res Ther 2014; 10(2): 381-3. DOI: 10.4103/0973-1482.136664

(c) 2020 National Journal of Health Sciences.

This is an open-access article. 